\title{
Temperature and Photoperiod Change the Flowering Process in Prunella vulgaris by Inducing Changes in Morphology, Endogenous Hormones, Carbon/Nitrogen Metabolites, and Gene Expression
}

\author{
Zanzan Li, Jinyu Hu, Hang Tang, Liping Cao, and Yuhang Chen \\ College of Pharmaceutical Sciences, Chengdu Medical College, Chengdu, Sichuan 610500, China \\ Qiaosheng Guo and Changlin Wang \\ Institute of Chinese Medicinal Materials, Nanjing Agricultural University, Nanjing, \\ Jiangsu 210095, China
}

\begin{abstract}
AdDitional INDEX words. leaf gas exchange, photosynthetic pigments, qRT-PCR, vernalization
Abstract. The spicas of Prunella vulgaris are widely used in the medical, beverage, and ornamental fields. Temperature and photoperiod are the two main ecological factors that determine the transformation of many plants from vegetative growth to reproductive growth. To explore the response of $P$. vulgaris flowering to temperature and photoperiod induction, we adopted vernalization long-day, vernalization short-day, nonvernalization long-day, and nonvernalization short-day treatments. The results showed that the morphology (total number of leaves, number of branches, number of leaves per branch, and branch length) of the vernalization treatment groups was significantly different from that of other nonvernalization groups, and the photosynthetic pigments, net photosynthetic rate, water use efficiency, stomatal conductance, intercellular $\mathrm{CO}_{2}$ concentration, and transpiration rate increased in the vernalization treatment group. However, the gibberellin $3\left(\mathbf{G A}_{3}\right)$, indole-3-acetic acid and zeatin riboside (ZR) contents were significantly increased under the short-day treatments groups, and the results were the same for the expression of endogenous hormone synthesis genes, except for abscisic acid (ABA). The flowering-related genes soc1, elf3, svp, ga20ox, and cryl were highly expressed under the vernalization short-day. Therefore, the induction of vernalization is more conducive to the increase in the photosynthetic rate. Temperature and photoperiod synergistically induced the synthesis and accumulation of starch, sugar, amino acids, and protein and affected the content of endogenous hormones and the expression of genes involved in their synthesis. $\mathrm{GA}_{3}$ and $\mathrm{ZR}$ had thresholds for their regulation of the flowering process in $P$. vulgaris, and high concentrations of ABA promoted flowering. Temperature and photoperiod coordinate the expression of the flowering-related genes soc1, elf3, svp, ga20ox, and cry1, thereby affecting the flowering process in $\boldsymbol{P}$. vulgaris.
\end{abstract}

Prunella vulgaris is a perennial herb of the Lamiaceae (Liao et al., 2012). The spica of $P$. vulgaris is commonly used in the medicine beverages or ornamental fields. $P$. vulgaris spicas have a wide range of biological activities in humans, including liver protection, antihyperglycemia, antiinflammation, and others (Feng et al., 2010; Hwang et al., 2013). The plant is also one of the main raw materials for a variety of herbal teas, and the flowers of $P$. vulgaris have seasonal ornamental value with high market demand.

Different sowing dates affect the growth periods of field crops (Ferrise et al., 2010; Robertson et al., 2004). For instance, compared with winter sowing, the longer vegetative period with

Received for publication 7 Oct. 2021. Accepted for publication 14 Nov. 2021. Published online 21 January, 2022.

This work was supported by the National Nature Science Foundation of China $(31500263,30772730$, and 81072986), the Sichuan Science and Technology Program (2019YJ0368 and 2020ZHFP0060), the Sichuan Provincial Administration of Traditional Chinese Medicine (2020JC0020), and Scientific Research Foundation of Chengdu Medical College (CYZ19-35).

Z.L. and J.H. contributed equally to this work.

Y.C. is the corresponding author. E-mail: chenyuhang221@126.com.

This is an open access article distributed under the CC BY-NC-ND license (https://creativecommons.org/licenses/by-nc-nd/4.0/). autumn sowing resulted in higher crop dry matter and nitrogen at flowering stage, which was associated with higher final grain yield (Ferrise et al., 2010). Further studies have shown that the effects of different sowing dates on the changes caused by temperature and photoperiod can reduce the number of Brassica napus flower buds and their degradation (Luo et al., 2018). The thermal effect and vernalization effect driven by temperature, as well as the photoperiod effect driven by the daylength, can synergistically affect the developmental pace of rape flowers (Luo et al., 2018). Vernalization and photoperiod affect the expression of antioxidant enzymes, metabolites, endogenous hormones, and flowering-related genes to synergistically induce bolting and flowering in Beta vulgaris (Liang, 2018).

The induction of flowers is triggered by environmental and endogenous stimuli, and its mechanism has been thoroughly studied in model plants (Liu et al., 2020b). The formation of floral organs is affected by a variety of hormones, of which auxin plays an important role in general floral-organ formation and the arrangement of different flower whorl patterns (Lampugnani et al., 2013); the gibberellin (GA) and cytokinin (CK) affect inflorescence formation by regulating cell proliferation and differentiation (Liu et al., 2020a). Furthermore, abscisic acid (ABA) treatment 
would lead to the later flowering of plants (Razoan et al., 2006). During flower development, the expression of genes involved in hormone signalling and carbon and nitrogen metabolism show obvious differences (Wang et al., 2019).

Sugar may exist in the form of a signalling molecule and may regulate plant growth, development and maturity in a manner similar to the action of plant hormones (Koch et al., 2000; Mornya et al., 2011); starch also has a role in this process (Seo et al., 2011; Yu et al., 2000). Furthermore, studies have found that carbon and nitrogen compounds affect flowering in plants by regulating gene expression (Paparelli et al., 2013; Zhang et al., 2019). On the basis of research in Arabidopsis thaliana, there are six flowering regulation pathways, including the photoperiod, gibberellin, autonomous, temperature-sensitive, vernalization, and age pathways (Khan et al., 2014). In addition, rate-limiting enzymes in hormone synthesis pathways have been discovered. For example, the expression of ipt can promote the synthesis of cytokinin (Reguera et al., 2013). The expression of agl24 can promote GA synthesis (Fang et al., 2018).

Through 3 years of field experiments, it was found that $P$. vulgaris sown in autumn in the first year will flower the next summer, but it will not bloom in the same year when planted in the spring of the second year. Temperature and photoperiod are the key factors affecting plant growth and development. Changes in the sowing date alter different environmental factors during plant growth (Ferrise et al., 2010; Luo et al., 2018). Analysis of the transcriptome of $P$. vulgaris at different sowing dates in the early stage showed that the expression levels of genes related to the flowering regulation pathway and the sugar and hormone metabolism pathways were significantly different in different samples (Y.H. Chen, Z.Z. Li, Q.S. Guo, C.L. Wang, L.P. Cao, H. Tang, and J.Y. Hu, unpublished data). Thus, sowing $P$. vulgaris in spring and autumn may result in different flowering characteristics due to the influence of different temperatures and photoperiods. However, the influencing factors related to photosynthesis, antioxidant enzyme activity, endogenous hormone content, metabolites and gene expression in this process are still unclear. Therefore, this experiment preliminarily sought to explain the effects of vernalization and photoperiod on the flowering process of $P$. vulgaris by measuring morphology, photosynthetic pigments, leaf gas exchange, $\mathrm{C} / \mathrm{N}$ metabolites, endogenous hormones, gene expression associated with flowering and hormone synthesis.

\section{Materials and Methods}

Plant materials. Mature seeds of $P$. vulgaris were procured from Bozhou City, Anhui Province, China, on 28 June 2020. The mature seeds of $P$. vulgaris were identified by Professor Guo Qiaosheng from the Institute of Chinese Medicinal Materials of Nanjing Agricultural University, Nanjing, China. The seeds were sown in $15 \times 15 \times 20$-cm plastic pots; each pot contained $800 \mathrm{~g}$ of sandy loam soil and vermiculite mixed in a ratio of $4: 1$, and 20 seeds were sown in each pot. When the plants had four true leaves, seedlings of a similar size were selected and transplanted into pots (same size and same soil mix used), with three plants evenly sown in each of 40 pots used. When the seedlings had eight true leaves, 20 pots were vernalized $\left(4^{\circ} \mathrm{C}\right.$ artificial climate box $)$ and 20 pots were not vernalized $\left(25^{\circ} \mathrm{C}\right.$ artificial climate box), with half of each group subjected to a $16 / 8 \mathrm{~h} \mathrm{light/dark}$ treatment and the other half subjected to an $8 /$
$16 \mathrm{~h} \mathrm{light/dark}$ treatment. The light intensity was set to $18 \mu \mathrm{mol} \cdot \mathrm{m}^{-2} \cdot \mathrm{s}^{-1}$, and the humidity was $65 \%$. After $14 \mathrm{~d}$, the temperature of each treatment was adjusted to $25 / 20^{\circ} \mathrm{C}$ (day/ night), while the other conditions remained unchanged, and the soil remained moist throughout the growth process. After $21 \mathrm{~d}$ of $25 / 20^{\circ} \mathrm{C}$ treatment, the leaves were collect, flash-frozen in liquid nitrogen, and stored in a freezer at $-80^{\circ} \mathrm{C}$ for later use. The four groups of treatments were vernalized long-day (VLD), vernalized short-day (VSD), nonvernalized long-day (NVLD), and nonvernalized short-day (NVSD), respectively.

Plant growth Parameters. The number of leaves, the number of branches (except for the main branches), and the number of leaves per branch were counted, and the branch length (the distance from the base of the stem to the top of the stem) was measured with a ruler.

Photosynthetic Pigment CONTENT AND Photosynthetic PARAMETERS. The content of photosynthetic pigments was determined according to the method of Chen et al. (2019). The photosynthetic pigment content was measured at 470,649, and 665 $\mathrm{nm}$ by weighing $0.2 \mathrm{~g}$ of fresh leaves and grinding the supernatant with anhydrous ethanol. Each treatment was repeated three times, and the pigment content was expressed in milligrams per gram.

The fourth leaf on the main stem of five plants was randomly selected, and net photosynthetic rate $\left(\mathrm{P}_{\mathrm{n}}\right)$, water use efficiency (WUE), stomatal conductance $\left(g_{\mathrm{S}}\right)$, intercellular $\mathrm{CO}_{2}$ concentration $\left(\mathrm{C}_{\mathrm{i}}\right)$, and transpiration rate $\left(\mathrm{T}_{\mathrm{r}}\right)$ were measured with a photosynthesis meter (FS-3080D; Fanshengkeji, Shijiazhuang, China) from 1100 to $1130 \mathrm{HR}$ on a sunny day (2 Aug. 2020). Light intensity, $\mathrm{CO}_{2}$ concentration, air temperature, and relative humidity were maintained at $1200 \mu \mathrm{mol} \cdot \mathrm{m}^{-2} \cdot \mathrm{s}^{-1}$ photosynthetically active radiation, $500 \pm 10 \mu \mathrm{M} \mathrm{CO}_{2}, 23 \pm 2^{\circ} \mathrm{C}$, and $65 \% \pm$ $1 \%$, respectively.

Soluble PRotein, SOluble SUgar and STARCH CONTENT. The content of soluble protein and soluble sugar were determined according to the method described by Wang (2006). The extraction of starches and the determination of their content were performed using commercial assay kits (Nanjing Jiancheng Bioengineering Institute, Nanjing, China). Fresh leave $(0.1 \mathrm{~g})$ ground into a powder using a mortar and pestle with liquid nitrogen, extract solution $(1 \mathrm{~mL})$ provided by test kit were added, and the samples were extracted at $80^{\circ} \mathrm{C}$ for $20 \mathrm{~min}$, which were centrifuged at $4000 \mathrm{~g}_{\mathrm{n}}$ for $5 \mathrm{~min}$ at $4{ }^{\circ} \mathrm{C}$, the supernatants were removed and the precipitates were left. Then, distilled water $(0.5$ $\mathrm{mL}$ ) were added to the precipitates, and gelatinized in $95^{\circ} \mathrm{C}$ water bath for $15 \mathrm{~min}$. After gelatinization, the samples were remained cool and stand, reagent two $(0.35 \mathrm{~mL})$ provided by test kit were added, and extracted for $10 \mathrm{~min}$ in $95^{\circ} \mathrm{C}$ water bath. After completion, distilled water $(0.85 \mathrm{~mL})$ were added, shaken and mixed well. After centrifugation $\left(4^{\circ} \mathrm{C}, 4000 g_{\mathrm{n}}, 10 \mathrm{~min}\right)$, the supernatant was collected and diluted 10 times. Finally, the contents of starch were operated according to the commercial assay kits (Nanjing Jiancheng Bioengineering Institute).

Free AMino ACID CONTENT. A sample of fresh leaves $(0.2 \mathrm{~g})$ were weighed into a mortar and ground to a powder using liquid nitrogen, and then $1.8 \mathrm{~mL}$ of $0.1 \mathrm{M}$ phosphate buffer $(\mathrm{pH}=7.8)$ was added to make a $10 \%$ homogenate and centrifuged at 3500 $g_{\mathrm{n}}$ for $10 \mathrm{~min}$ at $4{ }^{\circ} \mathrm{C}$. The supernatant was collected as a sample and analyzed for free amino acid content according to a commercial assay kit (Nanjing Jiancheng Bioengineering Institute). 
Plant endogenous hormone content. We measured the content of four plant endogenous hormones [gibberellin 3 $\left(\mathrm{GA}_{3}\right)$, indole-3-acetic acid (IAA), zeatin riboside (ZR), and ABA]. First, a $0.15-\mathrm{g}$ sample was weighed into a $5-\mathrm{mL}$ centrifuge tube. Then, steel balls and $1.5 \mathrm{~mL}$ of extraction solution (methanol:water:formic acid $=7.9: 2: 0.1$, containing a small amount of antioxidants) were added, and the sample was crushed for more than $3 \mathrm{~min}$. Samples were then treated with ultrasound on ice for $30 \mathrm{~min}$, vortexed at low speed, centrifuged, mixed, and extracted for $12 \mathrm{~h}$ at $4^{\circ} \mathrm{C}$. After centrifugation $\left(4^{\circ} \mathrm{C}, 12,000\right.$ $\left.g_{\mathrm{n}}, 20 \mathrm{~min}\right)$, the supernatant was collected. Extract $(1 \mathrm{~mL})$ was added to the filter residue, sonicated on ice for $30 \mathrm{~min}$, mixed, centrifuged, and extracted for $1 \mathrm{~h}$ at $4{ }^{\circ} \mathrm{C}$. After centrifugation $\left(4^{\circ} \mathrm{C}, 12,000 g_{\mathrm{n}}, 20 \mathrm{~min}\right)$, the supernatant was collected and combined with the extracts. The small column was fixed to the solid phase extraction instrument. The cartridge was activated with $4 \mathrm{~mL}$ of methanol and $2 \mathrm{~mL}$ of $0.1 \mathrm{M}$ ammonia solution in sequence, and the sample was passed through the cartridges (Oasis MAX; Waters Corp., Milford, MA). For small column elution, $2 \mathrm{~mL}$ of $0.1 \mathrm{M}$ aqueous ammonia solution and $2 \mathrm{~mL}$ of $0.1 \mathrm{M}$ aqueous ammonia- $60 \%$ methanol solution were used in sequence. Then, $2.5 \mathrm{~mL}$ of $1.25 \mathrm{M}$ formic acid- $70 \%$ methanol solution was added to completely elute the sample into a new centrifuge tube. The collected eluate was dried and concentrated into a powder. Each sample was reconstituted with $0.2 \mathrm{~mL}$ of starting mobile phase $(5 \%$ acetonitrile $+0.1 \%$ formic acid + $94.9 \%$ aqueous solution), vortexed and mixed. After filtering through a $0.2 \mu \mathrm{m}$ nylon membrane, the sample was tested on a high-performance liquid chromatograph (Acquity Ultra Performance Liquid Chromatographic System, Waters Corp.) and triple quadrupole mass spectrometer (Xevo TQ-S, Waters Corp.).

QUANTITATIVE REAL-TIME POLYMERASE CHAIN REACTION (QRTPCR) VALIDATION. The total RNA of each treatment $(0.1 \mathrm{~g}$ of fresh leaves) was extracted with a plant RNA extraction kit (MiniBEST; Takara, Dalian, China), and the mass and concentration of the total RNA were determined by $1.0 \%$ agarose gel electrophoresis and ultrafine spectrophotometry. Seven flowering genes were randomly selected, with actin as the internal reference gene, and primers were designed by Primer Premier 5.0 (Premier Biosoft International, Palo Alto, CA), as shown in (Supplemental Table 1). The reverse transcription reagent (PrimeScrIPT RT Reagent Kit with gDNA Eraser, Takara) was used for the synthesis of cDNA. The cDNA was diluted five times, and reverse-transcriptase polymerase chain reaction (RT-PCR) was performed with the TB Green Premix Ex Taq II (Tli RNaseH Plus) Kit (Takara). A RT-PCR platform (Step One Plus; Applied Biosystems, Waltham, MA) was applied to each 20-mL reaction system containing $10 \mathrm{~mL}$ of $2 \times$ TB Green Premix Ex Taq II, $0.8 \mathrm{~mL}$ of each upstream and downstream primer, $2 \mathrm{~mL}$ of cDNA, $0.4 \mathrm{~mL}$ of ROX Reference Dye $(50 \times)$, and $6 \mathrm{~mL}$ of $\mathrm{ddH}_{2} \mathrm{O}$. The qRT-PCR procedure was as follows: pre-denaturation at $95^{\circ} \mathrm{C}$ for $30 \mathrm{~s}$ followed by 40 cycles of denaturation at $95^{\circ} \mathrm{C}$ for $5 \mathrm{~s}$ and annealing at $60^{\circ} \mathrm{C}$ for $30 \mathrm{~s}$, with three biological repeats. The comparative cycle threshold $\left(2^{-\Delta \Delta \mathrm{Ct}}\right)$ was used to calculate the relative fold difference, and differences among the values were tested using one-way analysis of variance with Student's $t$ test at $P<0.05$.

Statistical analysis. Spreadsheet software (Microsoft Excel ver. 2016; Microsoft Corp. Redmond, WA) and statistical analysis software (IBM SPSS Statistics ver. 25.0 for Windows; IBM Corp., Armonk, NY) were used to perform double and single factor analyses of variance. The significant difference test was based on the Fisher's least significant difference method, and $P$ $<0.05$ indicated that a significant difference. Repeat three times for each statistic.

\section{Results}

EFFECTS OF TEMPERATURE AND PHOTOPERIOD ON THE BOTANICAL CHARACTERISTICS OF $\boldsymbol{P}$. VULGARIS. The total number of leaves was significantly increased, the number of branches was not significantly different, the number of leaves per branch was significantly reduced, and the branch length was shorter in the VLD group than in the VSD group (Table 1; Fig. 1). Compared with the NVSD group, there was no significant difference in these parameters for the NVLD group, except that the total number of leaves was significantly higher. When the vernalized group was compared with the nonvernalized group, the values for the preceding four traits were significantly increased. Vernalization and photoperiod synergistically and significantly affected the total number of leaves, number of leaves per branch, and branch lengths of $P$. vulgaris. The vernalization effect was greater than the photoperiod effect, but neither had an effect on the number of branches (Table 1).

Table 1. Effects of vernalization and photoperiod on the morphological characteristics of Prunella vulgaris $(\mathrm{n}=3)$.

\begin{tabular}{|c|c|c|c|c|}
\hline Treatment $^{\mathrm{z}}$ & Total leaves (no.) & Branches (no.) & Single-branch leaves (no.) & Branch length $(\mathrm{cm})$ \\
\hline & \multicolumn{4}{|c|}{ mean $\pm \mathrm{SD}$} \\
\hline Vernalized, long day & $36.0 \pm 2.00 \mathrm{a}^{\mathrm{y}}$ & $5.20 \pm 0.84 \mathrm{a}$ & $5.60 \pm 0.89 b$ & $0.60 \pm 0.09 \mathrm{~b}$ \\
\hline Vernalized, short day & $31.6 \pm 2.61 \mathrm{~b}$ & $5.20 \pm 0.84 \mathrm{a}$ & $7.60 \pm 0.89 \mathrm{a}$ & $3.60 \pm 0.31 \mathrm{a}$ \\
\hline Nonvernalized, long day & $19.0 \pm 2.28 \mathrm{c}$ & $2.40 \pm 0.55 \mathrm{~b}$ & $3.20 \pm 1.10 \mathrm{c}$ & $0.40 \pm 0.09 \mathrm{c}$ \\
\hline \multirow[t]{2}{*}{ Nonvernalized, short day } & $9.6 \pm 1.67 \mathrm{~d}$ & $1.80 \pm 0.84 \mathrm{~b}$ & $3.20 \pm 1.10 \mathrm{c}$ & $0.31 \pm 0.10 \mathrm{c}$ \\
\hline & \multicolumn{4}{|c|}{$F$ value $^{\mathrm{x}}$} \\
\hline Photoperiod & $49.1 *$ & $0.75 \mathrm{NS}$ & $218^{*}$ & $351 *$ \\
\hline Vernalization $\times$ photoperiod & $6.12 *$ & $0.75 \mathrm{NS}$ & $8.76^{*}$ & $390 *$ \\
\hline
\end{tabular}

${ }^{\mathrm{z}}$ Plants were vernalized by placing in $4{ }^{\circ} \mathrm{C}$ environmental chamber for $14 \mathrm{~d}$; nonvernalized plants were held at $25^{\circ} \mathrm{C}$ for $14 \mathrm{~d} . \mathrm{After} 14 \mathrm{~d}$, all plants were moved to $25 / 20^{\circ} \mathrm{C}$ (day/night) temperatures. Photoperiod treatments were long day $(16 / 8 \mathrm{~h} \mathrm{light/dark})$ and short day $(8 / 16 \mathrm{~h}$ light/dark) during and after vernalization treatments.

${ }^{\mathrm{y}}$ Different letters represent significant differences at $\alpha=0.05$ as analysis of variance (ANOVA).

${ }^{\mathrm{x}} F$ value significance indicated with asterisks $(*)$ is ANOVA at $\alpha=0.05$; NS indicates no significant differences. 


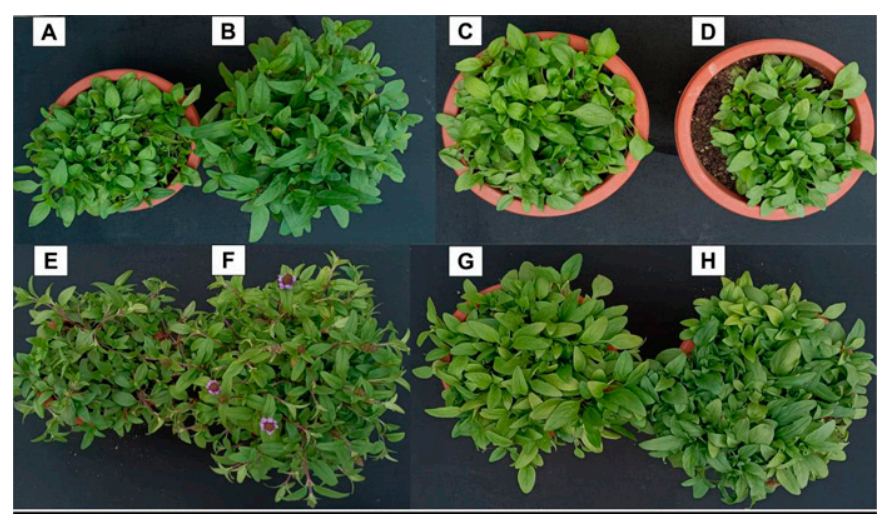

Fig. 1. Effects of different temperatures and photoperiods on the growth performance of Prunella vulgaris: (A-D) seedling stage; $(\mathbf{E}-\mathbf{H})$ flowering stage; (A, E) vernalization, long day; $(\mathbf{B}, \mathbf{F})$ vernalization, short day; $(\mathbf{C}$, G) nonvernalization, long day; (D, H) nonvernalization, long day.

EFFECTS OF TEMPERATURE AND PHOTOPERIOD ON THE PHOTOSYNTHETIC PIGMENT CONTENT IN $\boldsymbol{P}$. VULGARIS. The chlorophyll a (Chla), chlorophyll b (Chlb), and total chlorophyll $[\mathrm{Chl}(\mathrm{a}+\mathrm{b})]$ in the VLD group were significantly lower than those in the VSD group (except for carotenoid contents), and the Chla and carotenoid contents in the NVLD group were significantly higher than those in the NVSD group, whereas the content of Chlb showed an opposite trend, and there was no significant difference in the $\mathrm{Chl}(\mathrm{a}+\mathrm{b})$. The Chla, Chlb, $\mathrm{Chl}(\mathrm{a}+\mathrm{b})$, and carotenoid contents in the vernalized group were significantly higher than those in the nonvernalized group. Vernalization and photoperiod synergistically and significantly induced the synthesis of Chla, Chlb, $\mathrm{Chl}(\mathrm{a}+\mathrm{b})$, and carotenoids. The vernalization effect was greater than the photoperiod effect (Table 2)

EFFECTS OF TEMPERATURE AND PHOTOPERIOD ON THE PHOTOSYNTHETIC PARAMETERS OF $\boldsymbol{P}$. Vulgaris. After the VLD, VSD, NVLD, and NVSD treatments, the change trends of the photosynthetic parameters $\mathrm{P}_{\mathrm{n}}$ and $\mathrm{T}_{\mathrm{r}}$ in $P$. vulgaris were consistent in response to vernalization and photoperiod changes, and there were significant differences. The vernalization group had significantly higher values than the nonvernalization group, and the long-day group had significantly higher values than the short- day group. Vernalization and photoperiod synergistically aff ected the photosynthetic parameters $P_{n}$ and $T_{r}$, and the effect on $T_{r}$ due to the vernalization effect was stronger than the photoperiod effect, while the effect of $\mathrm{P}_{\mathrm{n}}$ showed an opposite trend. The change trends of WUE and $\mathrm{C}_{\mathrm{i}}$ were significant differences between the vernalization long-day group and the other three groups. Vernalization and photoperiod synergistically affected WUE and $\mathrm{C}_{\mathrm{i}}$, and vernalization and photoperiod had the same effect on WUE. The effect on $\mathrm{C}_{\mathrm{i}}$ due to the photoperiod was stronger than that due to vernalization. The $g_{\mathrm{S}}$ value was the highest for the VLD group, and vernalization and photoperiod both played a significant role, but there was no interaction between them (Table 3).

EFFECTS OF TEMPERATURE AND PHOTOPERIOD ON THE CONTENT OF CARBON AND NITROGEN COMPOUNDS IN $\boldsymbol{P}$. VULGARIS. The protein content, free amino acid content, starch content, and soluble sugar content of the VLD group were significantly higher than those of the NVLD group; moreover, the protein content, soluble sugar content, and starch content of the VSD group were significantly higher than those of the NVSD group (except for free amino acid content). The protein content and soluble sugar content of the long day group were significantly higher than those of the short day group, whereas the free amino acid content and starch content of the long day group were significantly lower than those of the short day group. Vernalization and photoperiod synergistically induced the synthesis of protein, free amino acids, starch and soluble sugars, and both played a significant role. The effect of photoperiod on protein, free amino acid, and starch synthesis was greater than that of vernalization, whereas soluble sugars showed an opposite pattern (Table 4).

EFFECTS OF TEMPERATURE AND PHOTOPERIOD ON THE CONTENT OF ENDOGENOUS HORMONES IN $\boldsymbol{P}$. VULGARIS. The contents of IAA, $\mathrm{ZR}$, and ABA in the VSD groups were significantly higher than those in the VLD group, but there was no significant difference in the $\mathrm{GA}_{3}$ content. The contents of the four hormones in the NVSD group were significantly higher than those in the NVLD group. The contents of IAA, $\mathrm{GA}_{3}, \mathrm{ZR}$, and $\mathrm{ABA}$ in the VLD group were significantly higher than those in the NVLD group. The $\mathrm{GA}_{3}$ and $\mathrm{ZR}$ contents of the VSD group were significantly lower than those of the NVSD group, and the difference in the IAA and ABA contents were opposite to that of $\mathrm{GA}_{3}$ and $\mathrm{ZR}$

Table 2. Effects of vernalization and photoperiod on the chlorophyll a (Chla), chlorophyll b (Chlb), and total chlorophyll [Chl(a+b)] content of Prunella vulgaris $(\mathrm{n}=3)$.

\begin{tabular}{|c|c|c|c|c|}
\hline Treatment $^{\mathrm{z}}$ & Chla (mg.g $\left.{ }^{-1}\right)$ & Chlb $\left(\mathrm{mg} \cdot \mathrm{g}^{-1}\right)$ & $\operatorname{Chl}(\mathrm{a}+\mathrm{b})\left(\mathrm{mg} \cdot \mathrm{g}^{-1}\right)$ & Carotenoid $\left(\mathrm{mg} \cdot \mathrm{g}^{-1}\right)$ \\
\hline \multicolumn{5}{|c|}{ mean $\pm \mathrm{SD}$} \\
\hline Vernalized, long day & $1.22 \pm 0.01 \mathrm{~b}^{\mathrm{y}}$ & $0.54 \pm 0.03 \mathrm{~b}$ & $1.75 \pm 0.03 \mathrm{~b}$ & $0.21 \pm 0.01 \mathrm{a}$ \\
\hline Nonvernalized, long day & $0.95 \pm 0.00 \mathrm{c}$ & $0.35 \pm 0.00 \mathrm{~d}$ & $1.30 \pm 0.00 \mathrm{c}$ & $0.19 \pm 0.00 \mathrm{c}$ \\
\hline Nonvernalized, short day & $0.84 \pm 0.02 \mathrm{~d}$ & $0.45 \pm 0.01 \mathrm{c}$ & $1.29 \pm 0.02 \mathrm{c}$ & $0.13 \pm 0.00 \mathrm{~d}$ \\
\hline \multicolumn{5}{|c|}{$F$ value $^{\mathrm{x}}$} \\
\hline Photoperiod & $44.6^{*}$ & $137 *$ & $235^{*}$ & $14.6^{*}$ \\
\hline Vernalization $\times$ photoperiod & $442 *$ & $9.59^{*}$ & $259 *$ & $38.1 *$ \\
\hline
\end{tabular}

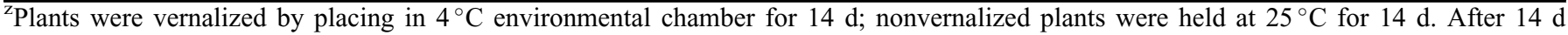
all plants were moved to $25 / 20^{\circ} \mathrm{C}$ (day/night) temperatures. Photoperiod treatments were long day $(16 / 8 \mathrm{~h} \mathrm{light/dark})$ and short day (8/16 h light/dark) during and after vernalization treatments.

${ }^{\mathrm{y}}$ Different letters represent significant differences at $\alpha=0.05$ as analysis of variance (ANOVA).

${ }^{\mathrm{x}} F$ value significance indicated with asterisks $(*)$ is ANOVA at $\alpha=0.05$. 
Table 3. Effects of vernalization and photoperiod on water use efficiency (WUE), net photosynthetic rate $\left(\mathrm{P}_{\mathrm{n}}\right)$, transpiration rate $\left(\mathrm{T}_{\mathrm{r}}\right)$, stomatal conductanc $\left(g_{\mathrm{S}}\right)$, and intercellular $\mathrm{CO}_{2}$ concentration $\left(\mathrm{C}_{\mathrm{i}}\right)$ of Prunella vulgaris $(\mathrm{n}=3)$.

\begin{tabular}{|c|c|c|c|c|c|}
\hline Treatment $^{\mathrm{z}}$ & 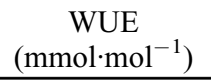 & $\begin{array}{c}\mathrm{P}_{\mathrm{n}} \\
{\left[\mathrm{CO}_{2}\left(\mu \mathrm{mol} \cdot \mathrm{m}^{-2} \cdot \mathrm{s}^{-1}\right)\right]}\end{array}$ & $\begin{array}{c}\mathrm{T}_{\mathrm{r}} \\
{\left[\mathrm{H}_{2} \mathrm{O}\left(\mathrm{mmol} \cdot \mathrm{m}^{-2} \cdot \mathrm{s}^{-1}\right)\right]}\end{array}$ & 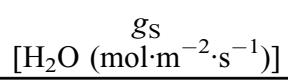 & $\begin{array}{c}\mathrm{C}_{\mathrm{i}} \\
\left(\mu \mathrm{L} \cdot \mathrm{L}^{-1}\right) \\
\end{array}$ \\
\hline & & & mean \pm SD & & \\
\hline Vernalized, long day & $4.15 \pm 0.15 \mathrm{a}^{\mathrm{y}}$ & $16.0 \pm 0.03 \mathrm{a}$ & $5.69 \pm 0.43 \mathrm{a}$ & $0.37 \pm 0.03 \mathrm{a}$ & $493 \pm 6.22 \mathrm{a}$ \\
\hline Vernalized, short day & $2.53 \pm 0.07 \mathrm{~b}$ & $10.0 \pm 0.23 \mathrm{~b}$ & $4.65 \pm 0.50 \mathrm{~b}$ & $0.25 \pm 0.03 \mathrm{~b}$ & $471 \pm 2.20 \mathrm{~b}$ \\
\hline Nonvernalized, long day & $1.55 \pm 0.11 \mathrm{~b}$ & $6.86 \pm 0.25 \mathrm{c}$ & $4.03 \pm 0.14 \mathrm{c}$ & $0.22 \pm 0.04 \mathrm{c}$ & $476 \pm 2.80 \mathrm{~b}$ \\
\hline \multirow[t]{2}{*}{ Nonvernalized, short day } & $1.06 \pm 0.04 \mathrm{~b}$ & $3.80 \pm 0.27 \mathrm{~d}$ & $1.65 \pm 0.09 \mathrm{~d}$ & $0.10 \pm 0.00 \mathrm{~d}$ & $472 \pm 3.05 \mathrm{~b}$ \\
\hline & & & $F$ value $^{\mathrm{x}}$ & & \\
\hline Vernalization & $378 *$ & $820 *$ & $234 *$ & $126^{*}$ & $20.5^{*}$ \\
\hline Photoperiod & $378^{*}$ & $2854^{*}$ & $126^{*}$ & $83.8^{*}$ & $55.4^{*}$ \\
\hline Vernalization $\times$ photoperiod & $378^{*}$ & $30.3^{*}$ & $19.7^{*}$ & $0.10 \mathrm{NS}$ & $26.9 *$ \\
\hline
\end{tabular}

${ }^{\mathrm{z} P l a n t s}$ were vernalized by placing in $4{ }^{\circ} \mathrm{C}$ environmental chamber for $14 \mathrm{~d}$; nonvernalized plants were held at $25^{\circ} \mathrm{C}$ for $14 \mathrm{~d} . \mathrm{After} 14 \mathrm{~d}$ all plants were moved to $25 / 20^{\circ} \mathrm{C}$ (day/night) temperatures. Photoperiod treatments were long day $(16 / 8 \mathrm{~h}$ light/dark) and short day ( $8 / 16 \mathrm{~h}$ light/dark) during and after vernalization treatments.

${ }^{\mathrm{y}}$ Different letters represent significant differences at $\alpha=0.05$ as analysis of variance (ANOVA).

${ }^{\mathrm{x}} F$ value significance indicated with asterisks $(*)$ is ANOVA at $\alpha=0.05$; NS indicates no significant differences.

contents. Vernalization and photoperiod synergistically induced the synthesis of $\mathrm{GA}_{3}, \mathrm{ABA}$, IAA and $\mathrm{ZR}$. Although vernalization had no significant effect on the $\mathrm{GA}_{3}$ and $\mathrm{ZR}$ content, photoperiod had a significant effect on the $\mathrm{GA}_{3}$ and $\mathrm{ZR}$ content, and both temperature and photoperiod had significant effects on the contents of IAA, $\mathrm{GA}_{3}, \mathrm{ZR}$, and ABA. The photoperiod effect on $\mathrm{IAA}, \mathrm{GA}_{3}$, and $\mathrm{ZR}$ was stronger than the vernalization effect, whereas the effect on ABA showed the opposite trend (Table 5).

EFFECTS OF TEMPERATURE AND PHOTOPERIOD ON THE EXPRESSION OF GENES RELATED TO ENDOGENOUS HORMONE SYNTHESIS IN P. VULGaRIS. The relative expression levels of trp, taal, ko, cyp735a, kao, and ipt in the VSD group were significantly higher than those in the VLD group, and the relative expression levels of those genes in the NVSD group were significantly higher than those in the NVLD group. The relative expression levels of taal, ipt, trp, nced, and kao in the VLD group were significantly lower than those in the NVLD group, whereas the relative expression levels of taal and ipt were not significantly different between the VSD and NVSD groups. The relative expression levels of taal, ipt, trp, nced, and kao in the VLD group were significantly lower than those in the NVLD group, whereas the relative expression levels of taal and ipt were not significantly different between the VSD and NVSD groups. The relative expression levels of trp and nced in the VSD group were significantly higher than those in the NVSD group, and the relative expression levels of kao and cyp $735 a$ showed an opposite pattern. Photoperiod had a greater effect on gene expression changes than vernalization. However, trp, nced, and ko expression were obviously induced by vernalization and photoperiod synergistically, whereas the expression of other genes had no significant interaction effect (Table 6).

EFFECTS OF TEMPERATURE AND PHOTOPERIOD ON THE EXPRESSION OF FLOWERING-RELATED GENES IN $\boldsymbol{P}$. VULGARIS. The relative expression levels of the flowering-related genes socl, elf3, svp, and ga20ox showed the same trend among the four treatments: the expression levels of socl, elf3, svp, and ga20ox in the VSD group were significantly higher than those in the NVSD group. The VLD group also showed significantly higher gene expression levels than the NVLD group. The relative expression of socl, elf3, svp, and ga20ox in the VLD group was significantly lower than that in the VSD group. The relative expression levels of socl, elf3, svp, and ga20ox in the NVLD group were not significantly different from those in the NVSD group (Table 7). Vernalization and photoperiod synergistically and significantly

Table 4. Effects of vernalization and photoperiod on carbon and nitrogen compounds of Prunella vulgaris $(\mathrm{n}=3)$.

\begin{tabular}{|c|c|c|c|c|}
\hline Treatment $^{\mathrm{z}}$ & Soluble protein $\left(\mathrm{g} \cdot \mathrm{L}^{-1}\right)$ & Free amino acids $\left(\mu \mathrm{g} \cdot \mathrm{mg}^{-1}\right.$ protein $)$ & Soluble sugar $\left(\mu g \cdot g^{-1}\right)$ & $\operatorname{Starch}\left(\mathrm{mg} \cdot \mathrm{g}^{-1}\right)$ \\
\hline & \multicolumn{4}{|c|}{ mean \pm SD } \\
\hline Vernalized, long day & $1.00 \pm 0.03 \mathrm{a}^{\mathrm{y}}$ & $7.43 \pm 0.16 \mathrm{c}$ & $3.99 \pm 0.01 \mathrm{a}$ & $3.65 \pm 0.04 \mathrm{c}$ \\
\hline Nonvernalized, long day & $0.94 \pm 0.01 \mathrm{~b}$ & $6.45 \pm 0.03 \mathrm{~d}$ & $1.51 \pm 0.00 \mathrm{c}$ & $3.28 \pm 0.01 \mathrm{~d}$ \\
\hline \multirow[t]{2}{*}{ Nonvernalized, short day } & $0.39 \pm 0.01 \mathrm{~d}$ & $45.5 \pm 0.18 \mathrm{a}$ & $1.38 \pm 0.01 \mathrm{~d}$ & $6.45 \pm 0.02 \mathrm{~b}$ \\
\hline & \multicolumn{4}{|c|}{$F$ value $^{\mathrm{x}}$} \\
\hline Photoperiod & $2012^{*}$ & $237,566^{*}$ & $2275^{*}$ & $78,894 *$ \\
\hline Vernalization $\times$ photoperiod & $99.7^{*}$ & $3460 *$ & $1574 *$ & $2883^{*}$ \\
\hline
\end{tabular}

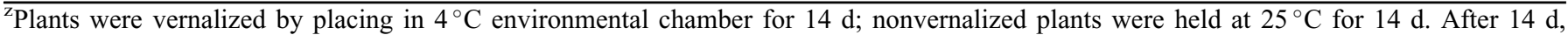
all plants were moved to $25 / 20^{\circ} \mathrm{C}$ (day/night) temperatures. Photoperiod treatments were long day $(16 / 8 \mathrm{~h} \mathrm{light/dark})$ and short day ( $8 / 16 \mathrm{~h}$ light/dark) during and after vernalization treatments.

${ }^{\mathrm{y}}$ Different letters represent significant differences at $\alpha=0.05$ as analysis of variance (ANOVA).

${ }^{\mathrm{x}} F$ value significance indicated with asterisks $(*)$ is ANOVA at $\alpha=0.05$. 
Table 5. Effects of vernalization and photoperiod on the gibberellin $\left(\mathrm{GA}_{3}\right)$, indole-3-acetic acid (IAA), zeatin riboside (ZR), and abscisic acid (ABA) content of Prunella vulgaris $(\mathrm{n}=3)$.

\begin{tabular}{|c|c|c|c|c|}
\hline Treatment $^{z}$ & IAA $\left(n g \cdot g^{-1}\right)$ & $\mathrm{GA}_{3}\left(\mathrm{ng} \cdot \mathrm{g}^{-1}\right)$ & ZR (ng. $\left.\mathrm{g}^{-1}\right)$ & $\mathrm{ABA}\left(\mathrm{ng} \cdot \mathrm{g}^{-1}\right)$ \\
\hline \multicolumn{5}{|c|}{ mean $\pm \mathrm{SD}$} \\
\hline Vernalized, long day & $28.8 \pm 0.61 \mathrm{c}^{\mathrm{y}}$ & $18.5 \pm 0.62 b$ & $31.4 \pm 0.15 \mathrm{c}$ & $1.58 \pm 0.02 b$ \\
\hline Vernalized, short day & $72.9 \pm 1.70 \mathrm{a}$ & $20.4 \pm 0.46 b$ & $35.3 \pm 0.78 \mathrm{~b}$ & $1.90 \pm 0.03 \mathrm{a}$ \\
\hline Nonvernalized, long day & $10.5 \pm 0.34 \mathrm{~d}$ & $7.77 \pm 0.24 \mathrm{c}$ & $22.1 \pm 0.83 \mathrm{~d}$ & $0.25 \pm 0.02 \mathrm{~d}$ \\
\hline Nonvernalized, short day & $37.2 \pm 0.49 b$ & $29.7 \pm 2.00 \mathrm{a}$ & $46.2 \pm 1.40 \mathrm{a}$ & $0.73 \pm 0.09 \mathrm{c}$ \\
\hline \multicolumn{5}{|c|}{$F$ value $^{\mathrm{x}}$} \\
\hline Vernalization & $2431 *$ & $1.65 \mathrm{NS}$ & $2.24 \mathrm{NS}$ & $2104 *$ \\
\hline Photoperiod & $4176^{*}$ & $365^{*}$ & $723^{*}$ & $218^{*}$ \\
\hline Vernalization $\times$ photoperiod & $255^{*}$ & $259^{*}$ & $380^{*}$ & $8.86^{*}$ \\
\hline
\end{tabular}

induced the expression of socl, elf3, svp, and ga20ox. The vernalization effect was stronger than the photoperiod effect, as shown in (Table 7). There were significant differences in the relative expression of cryl among the four treatments. The relative expression of cryl was the highest in the VSD group, and the photoperiod and vernalization effects were consistent with the responses of the abovementioned genes (Table 7).

\section{Discussion}

Flowering time is affected by many external factors, among which vernalization, photoperiod, and ambient temperature are the most significant (Xiao et al., 2013). Photoperiod not only regulates the differentiation and formation of fruit-bearing organs but also plays an important role in the flowering process (Torabi et al., 2020). In addition, vernalization plays an important role in the transformation from vegetative growth into reproductive growth in plants (Sarah et al., 2020). The results of this study showed that the effects of different photoperiod and vernalization treatments on the growth and flowering of $P$. vulgaris were complicated. It is worth noting that vernalization and photoperiod have a synergistic regulatory role in this process, but there are certain differences in the magnitudes of their respective effects and the degrees of interaction between different indicators.

EFFECTS OF TEMPERATURE AND PHOTOPERIOD ON THE BOTANICAL CHARACTERISTICS AND PHOTOSYNTHESIS OF $\boldsymbol{P}$. VULGARIS. The results of this experiment show that vernalization and photoperiod have different effects on the botanical characteristics of $P$. vulgaris. The total leaf number, branch number, leaf number per branch, and branch length of the VSD and VLD groups were higher than those of the nonvernalization groups. The number of leaves per branch and the branch length in the vernalization short-day group were higher than those in the other groups. Vernalization and photoperiod synergistically affected plant growth. Vernalization and short-day exposure are more conducive to P. vulgaris plant growth transformations, and vernalization plays a leading role. The intensity and range of light and temperature parameters affect photosynthesis, and photosynthetic pigments participate in photosynthesis to absorb and transmit light energy or cause primary photochemical reactions (Szymańska et al., 2017). By regulating the content of photosynthetic pigments, the photosynthetic capacity of plants in each flowering period can be adjusted to regulate the flowering period (Sun et al., 2015). The results of this experiment show that the photosynthetic pigment content

Table 6. Effects of vernalization and photoperiod on the expression of hormone synthesis genes in Prunella vulgaris leaves $(\mathrm{n}=3)$.

\begin{tabular}{|c|c|c|c|c|c|c|c|}
\hline Treatment $^{\mathrm{z}}$ & $\operatorname{trp}$ & cyp736a & taal & ko & kao & ipt & nced \\
\hline \multicolumn{8}{|c|}{ mean \pm SD } \\
\hline Vernalized, long day & $1.00 \pm 0.04 \mathrm{~d}^{\mathrm{y}}$ & $1.02 \pm 0.25 \mathrm{c}$ & $0.89 \pm 0.05 \mathrm{c}$ & $1.01 \pm 0.14 \mathrm{c}$ & $1.29 \pm 0.13 \mathrm{c}$ & $0.96 \pm 0.02 \mathrm{c}$ & $1.00 \pm 0.07 \mathrm{bc}$ \\
\hline Nonvernalized, long day & $1.46 \pm 0.03 \mathrm{c}$ & $0.48 \pm 0.11 \mathrm{~d}$ & $2.09 \pm 0.16 \mathrm{~b}$ & $0.33 \pm 0.05 \mathrm{~d}$ & $2.73 \pm 0.24 b$ & $1.12 \pm 0.30 \mathrm{~b}$ & $3.34 \pm 0.13 \mathrm{a}$ \\
\hline Nonvernalized, short day & $1.67 \pm 0.11 \mathrm{~b}$ & $7.98 \pm 0.31 \mathrm{~b}$ & $8.25 \pm 0.18 \mathrm{a}$ & $7.11 \pm 0.42 \mathrm{a}$ & $4.23 \pm 0.35 \mathrm{a}$ & $1.77 \pm 0.02 \mathrm{a}$ & $0.75 \pm 0.09 \mathrm{c}$ \\
\hline \multicolumn{8}{|c|}{$F$ value $^{\mathrm{x}}$} \\
\hline Photoperiod & $506^{*}$ & $209^{*}$ & $317^{*}$ & $1533^{*}$ & $40.2^{*}$ & $104 *$ & $167^{*}$ \\
\hline Vernalization $\times$ photoperiod & $281^{*}$ & $3.03 \mathrm{NS}$ & $0.80 \mathrm{NS}$ & $161^{*}$ & $0.73 \mathrm{NS}$ & $0.00 \mathrm{NS}$ & $262 *$ \\
\hline
\end{tabular}

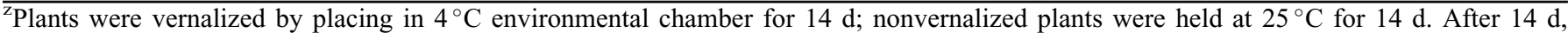
all plants were moved to $25 / 20^{\circ} \mathrm{C}$ (day/night) temperatures. Photoperiod treatments were long day $(16 / 8 \mathrm{~h} \mathrm{light/dark})$ and short day ( $8 / 16 \mathrm{~h}$ light/dark) during and after vernalization treatments.

${ }^{\mathrm{y}}$ Different letters represent significant differences at $\alpha=0.05$ as analysis of variance (ANOVA).

${ }^{\mathrm{x}} F$ value significance indicated with asterisks $\left({ }^{*}\right)$ is ANOVA at $\alpha=0.05$; NS indicates no significant differences. 
Table 7. Effects of vernalization and photoperiod on flowering gene expression in Prunella vulgaris leaves $(\mathrm{n}=3)$.

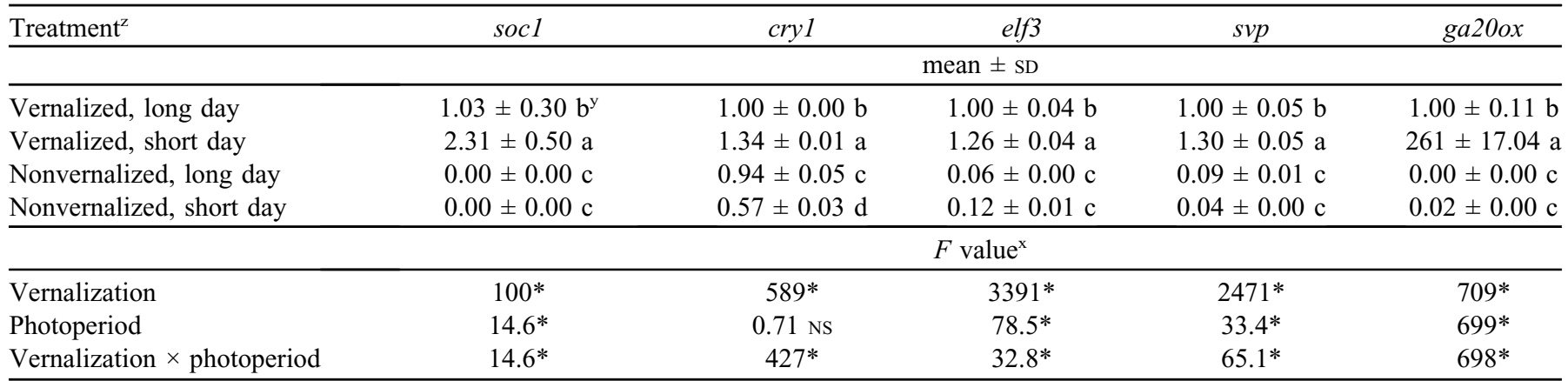

${ }^{\mathrm{z}}$ Plants were vernalized by placing in $4{ }^{\circ} \mathrm{C}$ environmental chamber for $14 \mathrm{~d}$; nonvernalized plants were held at $25^{\circ} \mathrm{C}$ for $14 \mathrm{~d} . \mathrm{After} 14 \mathrm{~d}$ all plants were moved to $25 / 20^{\circ} \mathrm{C}$ (day/night) temperatures. Photoperiod treatments were long day $(16 / 8 \mathrm{~h} \mathrm{light/dark})$ and short day (8/16 h light/dark) during and after vernalization treatments.

${ }^{\mathrm{y}}$ Different letters represent significant differences at $\alpha=0.05$ as analysis of variance (ANOVA).

${ }^{\mathrm{x}} F$ value significance indicated with asterisks (*) is ANOVA at $\alpha=0.05$; Ns indicates no significant differences.

and photosynthesis intensity of the vernalization group are higher than those of the other groups. The photosynthetic pigment content is the highest in the vernalization short-day group. Low temperature and short-day interact to promote photosynthetic pigment synthesis, which provides the possibility for later nutrient synthesis. Increased photosynthesis intensity can also provide more energy reserves for plant flowering (Zhou, 2010). The higher the chlorophyll content is, the greater the potential for improving photosynthetic efficiency (Guo et al., 2019). However, in this study, the changes in the chlorophyll content and photosynthetic efficiency under vernalization conditions were inconsistent, which may be due to the amount of photosynthetic pigments per unit weight in the vernalization short-day treatment group being higher. However, the leaves of the VSD group were larger, resulting in a relatively low amount of photosynthetic pigments per unit area, and the amount of chlorophyll per unit area was not high; thus, the photosynthetic activity was relatively reduced.

EFFECTS OF TEMPERATURE AND PHOTOPERIOD ON THE CARBON AND NITROGEN COMPOUNDS OF $\boldsymbol{P}$. VULGARIS. On the basis of the hypothesis that photosynthate promotes flowering and a high nitrogen supply suppresses reproductive development, a high $\mathrm{C} /$ $\mathrm{N}$ ratio should promote the floral transition (Corbesier et al., 2001, 2002). Sugar is used as an energy source to regulate the transformation from vegetative growth to reproductive growth (Shalom et al., 2014). Sucrose may promote the transition to flowering by upregulating the expression of some floweringassociated genes, such as socl and agl24 (Xing et al., 2015). Increased amino acid and sucrose export was observed in the shoot apical meristem (Corbesier et al., 2001). In this experiment, the analysis of total amino acid, soluble protein, starch, and soluble sugar contents showed that the four indexes in $P$. vulgaris were all affected by the interaction of light and temperature, and the first three were more affected by photoperiod than by vernalization. The total amino acid content is higher in the short-day group than in the long-day group, whereas the soluble protein showed the opposite pattern. This result may be because amino acids can be converted into proteins. Under vernalization conditions, the high protein content provides nutrients for the plant, but the high content under nonvernalization treatments did not play this role. This phenomenon may be because different treatments activate proteins with different functions. Low temperature is beneficial for the rapid accumulation of carbohydrates (Janská et al., 2010; Theocharis et al., 2012). This study found that the soluble sugar content in the vernalized group was significantly higher than that in the nonvernalized group. The higher total chlorophyll content in the vernalized group may contribute to this result. Sugar accumulation provides nutrient reserves for the promotion of reproductive growth in $P$. vulgaris.

EFFECTS OF TEMPERATURE AND PHOTOPERIOD ON ENDOGENOUS HORMONES IN $\boldsymbol{P}$. VULGARIS. The levels of various endogenous hormones play an important role in the process of flower bud differentiation, and there is a dynamic balance between these hormones (Fan et al., 2018; Mornya and Cheng, 2011). Through mutual promotion or mutual antagonism, these hormones jointly regulate the development of plant flower buds. The current analysis showed that the $\mathrm{GA}_{3}$ and $\mathrm{ZR}$ content induced the flowering process of $P$. vulgaris based on a threshold, and the change would not be induced if the content was greater than the threshold or less than the threshold; thus, the higher concentration of these hormones promoted the flowering process within a certain threshold. The content of endogenous hormones is affected synergistically by photoperiod and temperature. The photoperiod effect has a much greater impact on $\mathrm{GA}_{3}$ and $\mathrm{ZR}$ than the vernalization effect. The IAA content in $P$. vulgaris leaves changes significantly over time, but it is not completely consistent with the overall trend of plant growth. ABA may not play a leading role in promoting the flowering of $P$. vulgaris. The ABA content of $P$. vulgaris leaves in the vernalization short-day group was significantly higher than that of the other groups. The ABA content gradually increased when the Prunus persica flower bud entered the differentiation phase, and after the morphological differentiation phase, the ABA content gradually decreased (Garcia-Pallas et al., 2001). This result further proves that a high ABA content promotes flowering in P. vulgaris. Moreover, the synthesis of $\mathrm{ABA}$ is affected by photoperiod, as the vernalization has a greater impact. This result indicates that different endogenous hormones in $P$. vulgaris have different responses to temperature and photoperiod - that is, different hormones respond differently to the same treatment (Guan et al., 2019). The precise threshold range of each hormone in the promotion of $P$. vulgaris flowering and their mutual coordination have not been studied in depth.

EFFECTS OF TEMPERATURE AND PHOTOPERIOD ON GENES REGULATING ENDOGENOUS HORMONE SYNTHESIS IN $\boldsymbol{P}$. VULGARIS. Working alone or in combination, hormones are able to promote flowering by epigenetic regulation (Campos-Rivero et al., 2017). 
In recent years, various endogenous hormone synthesis pathway genes have been continuously revealed. For example, auxin synthesis is regulated by trp, yuccas, taal, and others; gibberellin synthesis is regulated by ko, kao, ga3ox, and others $(\mathrm{Li}$ and $\mathrm{Li}$, 2019); and cytokinin synthesis is regulated by genes such as ipt (Reguera et al., 2013). Through the analysis of the expression of endogenous hormone-related genes, we found that the expression trends of the genes that regulate auxin synthesis, trp and taal, are similar to the trend in the auxin content. The short-day exposure group had a higher level of gene expression than the long-day exposure group, and the photoperiod effect was greater than the vernalization effect. trp and taal can effectively regulate auxin synthesis. The expression trends of genes that regulate gibberellin synthesis, kao and $\mathrm{ko}$, are similar to those that regulate the auxin content. They had higher expression in the shortday group than in the long-day group. kao and $k o$ can effectively regulate auxin synthesis and are synergistically affected by photoperiod and temperature. The expression trends of genes that regulate cytokinin synthesis, ipt and cyp $735 a$, were similar to trends in the cytokinin content. Both are more highly expressed in the short-day group than in the long-day group. ipt and cyp $735 a$ can effectively regulate the synthesis of cytokinin and are also affected by the synergistic effect of photoperiod and temperature. The expression of nced is affected by temperature and photoperiod, but it has a low consistency with changes in the ABA content. This phenomenon may be because there are many genes involved in regulating the $\mathrm{ABA}$ synthesis process. nced does not play a leading role in the ABA synthesis of $P$. vulgaris. The specific regulatory mechanism needs further verification.

EFFECTS OF TEMPERATURE AND PHOTOPERIOD ON THE FLOWERING-RELATED GENES IN $\boldsymbol{P}$. VULGARIS. In the model plant $A$. thaliana, six major flowering pathways have been defined by classical genetic analyses (Fornara et al., 2010). The vernalization and ambient temperature pathways are more important in many temperate species. Under the action of low temperature and vernalization, $f l c$ expression was downregulated, which indirectly activated $f t$ and $s o c 1$, and then induced the expression of characteristic genes in the floral meristem to initiate flowering (Sheldon et al., 2000). In addition, other studies have shown that changes in hormone concentration can promote the expression of pssocl, psspl9, and pssvp in peony flowers (Guan et al., 2019). In this experiment, through the analysis of the expression of genes related to multiple pathways regulating flowering, it was found that the expression levels of socl, elf3, svp, ga20ox, and $c r y 1$ in the vernalization short-day group were significantly higher than those in the other groups. This result indicates that the vernalization effect is stronger than the photoperiod effect, and vernalization and short-day sunlight synergistically induce the expression of socl, elf3, svp, ga20ox, and cryl to promote flowering. Although the aforementioned genes belong to different flowering control pathways, they all reach their maximum expression levels under vernalization and short-day conditions. The possible reason for this type of expression pattern is that flowering control genes often do not act alone but are related to each other to jointly regulate the flowering process. However, how these genes interact with each other requires further study.

\section{Conclusions}

Temperature and photoperiod are closely related to promotion of the flowering process in $P$. vulgaris and have intricate effects on the contents of carbon and nitrogen compounds, photosynthetic parameters, hormone and hormone synthesis pathwayrelated genes, and the expression of flowering pathway-related genes. In short, both temperature and photoperiod have obvious effects, and the two work synergistically. Vernalization may be beneficial to the accumulation of chlorophyll in P. vulgaris, and the enhancement of photosynthesis may promote sugar synthesis. The expression of the flowering-related genes socl, elf 3 , svp, ga20ox, and cryl in the vernalization group was higher than that in the nonvernalization group. Among these treatments, short days resulted in significantly higher expression than long days, and the vernalization short-day treatment was more conducive to the advancement of the flowering process in $P$. vulgaris. The contents of the endogenous hormones IAA, $\mathrm{ZR}$, and $\mathrm{GA}_{3}$ and the corresponding expression levels of genes involved in their synthesis, such as trp and taal, ipt and cyp 735a, and kao and ko, were similar. The effects of these factors on the advancement of $P$. vulgaris flowering processes may be influenced by each other and have a threshold. This result provides us with new ideas for further research on the flowering mechanism of $P$. vulgaris.

\section{Literature Cited}

Campos-Rivero, G., P. Osorio-Montalvo, R. Sánchez-Borges, R. Us-Camas, F. Duarte-Aké, and C. De-la-Peña. 2017. Plant hormone signaling in flowering: An epigenetic point of view. J. Plant Physiol. 214:16-27, https://doi.org/10.1016/j.jplph.2017.03.018.

Chen, H.Y., X.R. Zhang, Q.S. Guo, L.P. Cao, Q. Qin, C. Li, M. Zhao, and W.M. Wang. 2019. Plant morphology, physiological characteristics, accumulation of secondary metabolites and antioxidant activities of Prunella vulgaris L. under UV solar exclusion. Biol. Res. 52:17, https://doi.org/10.1186/s40659-019-0225-8.

Corbesier, L., A. Havelange, P. Lejeune, G. Bernier, and C. Périlleux. 2001. N content of phloem and xylem exudates during the transition to flowering in Sinapis alba and Arabidopsis thaliana. Plant Cell Environ. 24:367-375, https://doi.org/10.1046/j.1365-3040.2001.00683.x.

Corbesier, L., G. Bernier, and C. Périlleux. 2002. C:N ratio increases in the phloem sap during floral transition of the long-day plants Sinapis alba and Arabidopsis thaliana. Plant Cell Physiol. 43:684-688, https://doi.org/10.1093/pcp/pcf071.

Fan, L.J., M.Q. Chen, B. Dong, N.H. Wang, Q. Yu, X.L. Wang, L.J. Xuan, Y.L. Wang, S.Z. Zhang, and Y.M. Shen. 2018. Transcriptomic analysis of flower bud differentiation in Magnolia sinostellata. Genes (Basel) 9:212, https://doi.org/10.3390/genes9040212.

Fang, S., K. Gao, W. Hu, J.L. Snider, S.S. Wang, B.L. Chen, and Z.G. Zhou. 2018. Chemical priming of seed alters cotton floral bud differentiation by inducing changes in hormones, metabolites and gene expression. Plant Physiol. Biochem. 130:633-640, https://doi.org/ 10.1016/j.plaphy.2018.08.010.

Feng, L.A., X.B. Jia, F. Shi, and Y. Chen. 2010. Identification of two polysaccharides from Prunella vulgaris L. and evaluation on their anti-lung adenocarcinoma activity. Molecules 15:5093-5103, https:// doi.org/10.3390/molecules15085093.

Ferrise, R., A. Triossi, P. Stratonovitch, M. Bindi, and P. Martre. 2010. Sowing date and nitrogen fertilisation effects on dry matter and nitrogen dynamics for durum wheat: An experimental and simulation study. Field Crops Res. 117:245-257, https://doi.org/10.1016/j. fcr.2010.03.010.

Fornara, F., A. de Montaigu, and G. Coupland. 2010. SnapShot: Control of flowering in Arabidopsis. Cell 141:550, https://doi.org/ 10.1016/j.cell.2010.04.024.

Garcia-Pallas, I., J. Val, and A. Blanco. 2001. The inhibition of flower bud differentiation in 'Crimson Gold' nectarine with $\mathrm{GA}(3)$ as an alternative to hand thinning. Scientia Hort. 90:265-278, https://doi. org/10.1016/S0304-4238(01)00229-1. 
Guan, Y.R., J.Q. Xue, Y.Q. Xue, R.W. Yang, S.L. Wang, and X.X. Zhang. 2019. Effect of exogenous $\mathrm{GA}_{3}$ on flowering quality, endogenous hormones, and hormone- and flowering-associated gene expression in forcing-cultured tree peony (Paeonia suffruticosa). J. Integr. Agric. 18:1295-1311, https://doi.org/10.1016/S2095-3119(18)62131-8. Guo, D.Q., L.F. Lu, M.S. Yin, and C.J. Meng. 2019. Dynamic trends of nutrients among clones of Eucalyptus dunnii at flowering and fruiting period. Guangxi For. Sci. 48:501-504, https://doi.org/ 10.19692/j.cnki.gfs.2019.04.014.

Hwang, Y.J., E.J. Lee, H.R. Kim, and K.A. Hwang. 2013. NF-kappa B-targeted anti-inflammatory activity of Prunella vulgaris var. lilacina in macrophages RAW 264.7. Int. J. Mol. Sci. 14:21489-21503, https://doi.org/10.3390/ijms141121489.

Janská, A., P. Marsík, S. Zelenková, and J. Ovesná. 2010. Cold stress and acclimation what is important for metabolic adjustment? Plant Biol. 12:395-405, https://doi.org/10.1111/j.1438-8677.2009.00299.x.

Khan, M.R.G., X.Y. Ai, and J.Z. Zhang. 2014. Genetic regulation of flowering time in annual and perennial plants. Wires RNA 5:347-359, https://doi.org/10.1002/wrna.1215.

Koch, K.E., Z. Ying, Y. Wu, and T.A. Wayne. 2000. Multiple paths of sugar-sensing and a sugar/oxygen overlap for genes of sucrose and ethanol metabolism. J. Expt. Bot. 51:417-427, https://doi.org/ 10.1093/jexbot/51.suppl_1.417.

Lampugnani, E.R., K. Aydin, and D.R. Smyth. 2013. Auxin controls petal initiation in Arabidopsis. Development 140:185-194, https:// doi.org/10.1242/dev.084582

Li, J. and C.Y. Li. 2019. Seventy-year major research progress in plant hormones by Chinese scholars. Sci. Sin. Vitae 49:1227-1281.

Liang, N.G. 2018. Research on bolting and flowering related molecular mechanism of sugar beet induced by temperature and light. Harbin Inst. Technol., Harbin, China.

Liao, L., Q.S. Guo, Z.Y. Wang, L. Liu, and Z.B. Zhu. 2012. Genetic diversity analysis of Prunella vulgaris in China using ISSR and SRAP markers. Biochem. Syst. Ecol. 45:209-217, https://doi.org/ 10.1016/j.bse.2012.07.030.

Liu, H., G. Li, X.J. Yang, H.N.J. Kuijer, W.Q. Liang, and D.B. Zhang. 2020a. Transcriptome profiling reveals phase-specific gene expression in the developing barley inflorescence. Crop J. 8:71-86, https:// doi.org/10.1016/j.cj.2019.04.005.

Liu, Y., X.Y. Hao, Q.H. Lu, W.F. Zhang, H.J. Zhang, L. Wang, Y.J. Yang, B. Xiao, and X.C. Wang. 2020b. Genome-wide identification and expression analysis of flowering-related genes reveal putative floral induction and differentiation mechanisms in tea plant (Camellia sinensis). Genomics 112:2318-2326, https://doi.org/10.1016/j. ygeno.2020.01.003.

Luo, T., J. Zhang, M.N. Khan, J.H. Liu, Z.H. Xu, and L.Y. Hu. 2018. Temperature variation caused by sowing dates significantly affects floral initiation and floral bud differentiation processes in rapeseed (Brassica napus L.). Plant Sci. 271:40-51, https://doi.org/10.1016/j. plantsci.2018.03.004.

Mornya, P., F.Y. Cheng, and H.Y. Li. 2011. Chronological changes in plant hormone and sugar contents in cv.Ao-Shuang autumn flowering tree peony. Hort. Sci. (Prague) 38:104-112, https://doi.org/10.17221/ 11/2011-HORTSCI.

Mornya, P. and F.Y. Cheng. 2011. The levels of hormone and carbohydrate in autumn and non-autumn flower. Can. J. Plant Sci. 91:991-998, https://doi.org/10.4141/CJPS2011-043.

Paparelli, E., S. Parlanti, S. Gonzali, G. Novi, L. Mariotti, N. Ceccarelli, J.T. van Dongen, K. Kölling, S.C. Zeeman, and P. Perata. 2013. Nighttime sugar starvation orchestrates gibberellin biosynthesis and plant growth in Arabidopsis. Plant Cell 25:3760-3769, https://doi. org/10.1105/tpc.113.115519.

Razoan, F.A., A. EI-Kereamv, S.R. Abrams, and R.D. Hill. 2006. The RNA-binding protein FCA is an abscisic acid receptor. Nature 439:290-294, https://doi.org/10.1038/nature04373.
Reguera, M., Z. Peleg, Y.M. Abdeltawab, E.B. Tumimbang, C.A. Delatorre, and E. Blumwald. 2013. Stress-induced cytokinin synthesis increases drought tolerance through the coordinated regulation of carbon and nitrogen assimilation in rice. Plant Physiol. 163:16091622, https://doi.org/10.1104/pp.113.227702.

Robertson, M.J., J.F. Holland, and R. Bambach. 2004. Response of canola and Indian mustard to sowing date in the grain belt of northeastern Australia. Aust. J. Expt. Agr. 44:43-52, https://doi.org/ 10.1071/ea02214.

Sarah, M., K. Avneesh, H. Daniela, W. Bernd, and M. Siegbert. 2020. The transition to flowering in winter rapeseed during vernalization. Plant Cell Environ. 44:506-518, https://doi.org/10.1111/pce.13946.

Seo, P.J., J. Ryu, S.K. Kang, and C.M. Park. 2011. Modulation of sugar metabolism by an INDETERMINATE DOMAIN transcription factor contributes to photoperiodic flowering in Arabidopsis. Plant J. 65:418-429, https://doi.org/10.1111/j.1365-313X.2010.04432.x.

Shalom, L., S. Samuels, N. Zur, L. Shlizerman, A. Doron-Faigenboim, E. Blumwald, and A. Sadka. 2014. Fruit load induces changes in global gene expression and in abscisic acid (ABA) and indole acetic acid (IAA) homeostasis in citrus buds. J. Expt. Bot. 65:3029-3044, https://doi.org/10.1093/jxb/eru148.

Sheldon, C.C., D.T. Rouse, E.J. Finnegan, W.J. Peacock, and E.S. Dennis. 2000. The molecular basis of vernalization: The central role of FLOWERING LOCUS $C$ (FLC). Proc. Natl. Acad. Sci. USA 97:3753-3758, https://doi.org/10.1073/pnas.97.7.3753.

Sun, W., Y.Z. Pan, and L.L. Qin. 2015. Effects of $\mathrm{GA}_{3}$ and CEPA on photosynthetic characteristics and antioxidant enzymes in the flowering phase and the flowering response of Lilium casa blanca. Acta Pratac. Sin. 24:73-84.

Szymańska, R., I. Ślesak, A. Orzechowska, and J. Kruk. 2017. Physiological and biochemical responses to high light and temperature stress in plants. Environ. Exp. Bot. 139:165-177, https://doi.org/ 10.1016/j.envexpbot.2017.05.002.

Theocharis, A., C. Clément, and E.A. Barka. 2012. Physiological and molecular changes in plants grown at low temperatures. Planta 235:1091-1105, https://doi.org/10.1007/s00425-012-1641-y.

Torabi, B., M. Adibnya, A. Rahimi, and A. Azari. 2020. Modeling flowering response to temperature and photoperiod in safflower. Ind. Crops Prod. 151:112474, https://doi.org/10.1016/j.indcrop.2020.112474.

Wang, M., D. Xi, Y. Chen, C.C. Zhu, Y.Q. Zhao, and G.M. Geng. 2019. Morphological characterization and transcriptome analysis of pistillate flowering in pecan (Carya illinoinensis). Scientia Hort. 257:108674, https://doi.org/10.1016/j.scienta.2019.108674.

Wang, X.K. 2006. Experimental principles and techniques of plant physiology and biochemistry. Higher Educ. Press, Beijing, China.

Xiao, D., J.J. Zhao, X.L. Hou, R.K. Basnet, D.P.D. Carpio, N.W. Zhang, J. Bucher, K. Lin, F. Cheng, X.W. Wang, and G. Bonnema. 2013. The Brassica rapa FLC homologue FLC2 is a key regulator of flowering time, identified through transcriptional co-expression networks. J. Expt. Bot. 64:4503-4516, https://doi.org/10.1093/jxb/ert264.

Xing, L.B., D. Zhang, Y.M. Li, Y.W. Shen, C.P. Zhao, J.J. Ma, N. An, and M.Y. Han. 2015. Transcription profiles reveal sugar and hormone signaling pathways mediating flower induction in apple (Malus domestica Borkh.). Plant Cell Physiol. 56:364-369, https:// doi.org/10.1093/pcp/pcv124.

Yu, T.S., W.L. Lue, S.M. Wang, and J. Chen. 2000. Mutation of Arabidopsis plastid phosphoglucose isomerase affects leaf starch synthesis and floral initiation. Plant Physiol. 123:319-326, https://doi.org/ 10.1104/pp.123.1.319.

Zhang, Z.W., Y.F. Fu, Y.H. Zhou, C.Q. Wang, T. Lan, G.D. Chen, J. Zeng, Y.E. Chen, M. Yuan, S. Yuan, and J.Y. Hu. 2019. Nitrogen and nitric oxide regulate Arabidopsis flowering differently. Plant Sci. 284:177-184, https://doi.org/10.1016/j.plantsci.2019.04.015.

Zhou, X.L. 2010. The role of endogenous anti-oxidant system on flower opening and senescence process in tree peony. Beijing For. Univ., Beijing, China. 
Supplemental Table 1. Details of the primers used in the quantitative reverse-transcription polymerase chain reaction analysis.

\begin{tabular}{|c|c|c|}
\hline Gene name & Forward sequence $\left(5^{\prime}-3^{\prime}\right)$ & Reverse sequence $\left(5^{\prime}-3^{\prime}\right)$ \\
\hline $\operatorname{actin}^{\mathrm{z}}$ & GACCAGCTCTGCTGTGGAGA & ATGGCTGGAAGAGGACCTCAG \\
\hline ga20ox (Cluster-7524.32729) & CGCGTATCGGGAGATGGATG & CACGGCAGCTTTGTGGAAAA \\
\hline svp (Cluster-9289.0) & CGTCGCCCTCCTCATCTTCT & ATGCCTTCCTAGTATTTCCTTCAC \\
\hline elf3 (Cluster-7524.11783) & GGCTCCTCTTCCCAACACTT & TCCTCAAACCTCCAGCCTTC \\
\hline cryl (Cluster-7524.15863) & GAGGCAGAGCCAAGAAGAGC & GAGGGTGACCAAACTGGAACTA \\
\hline socl (Cluster-7524.33732) & AAATGGTGAGGGGAAAAGTG & TGCATCGCACAGAACTGAGA \\
\hline $\operatorname{trp}($ Cluster-7524.14649) & GCACTCCTATTGGTCGCT & GTTTCCCCTGTTGTTTCG \\
\hline taal (Cluster-8984.0) & AGTGTTGCGAGGAAGATG & GCGGCTGTAGTGAAAGAA \\
\hline cyp735a (Cluster-7524.2696) & GATTGTATCCCTGGTCTTCT & GGTTACCGTAGGTCTTGG \\
\hline ipt (Cluster-7524.2701) & GATTCTGCTATTCCGCTTAT & TATCTGGTCTCCCGCTCT \\
\hline nced (Cluster-16623.0) & CGCCATCACCGAGAACTT & TCGCCGCACTCTATCCAC \\
\hline ko (Cluster-7524.7042) & AGAGGCTATGGTCACGAA & AGACATTTGGCAGCACTA \\
\hline kao (Cluster-13435.0) & TTGTAGATGGGATGGATT & ATCTTGGCTAGATCGTTT \\
\hline
\end{tabular}

${ }^{\mathrm{z}}$ Reference gene for qRT-PCR analysis. 